\title{
State-of-the-art review on fracture analysis of concrete structural components
}

\author{
A RAMA CHANDRA MURTHY*, G S PALANI and \\ NAGESH R IYER
}

Structural Engineering Research Centre, CSIR Campus, Taramani, Chennai 600113

e-mail: [murthyarc,pal,nriyer]@sercm.org

MS received 1 August 2006; revised 20 October 2008

\begin{abstract}
This paper presents a critical review of literature on fracture analysis of concrete structural components. Review includes various fracture models, tension softening models, methodologies for crack growth analysis and remaining life prediction. The widely used fracture models which are based on fictitious crack approach and effective elastic crack approach have been explained. Various tension softening models such as linear, bi-linear, tri-linear, etc. have been presented with appropriate expressions. From the critical review of models, it has been observed that some of the models have complex expressions involving many parameters. There is a need to develop some more generalised models. Studies have been conducted on crack growth analysis and remaining life prediction using linear elastic fracture mechanics (LEFM) principles. From the studies, it has been observed that there is significant difference between predicted and experimental observations. The difference in the values is attributed to not considering the tension softening effect in the analysis.
\end{abstract}

Keywords. Concrete fracture; concrete fracture models; tension softening models; crack growth; remaining life.

\section{Introduction}

Concrete is a widely used material that is required to withstand a large number of cycles of repeated loading in structures such as highways, airports, bridges and ocean structures. The present state-of-the-art of designing such structures against the distress due to fatigue loading is largely empirical, gained by many years of experience. As long as the designer is dealing with structures made of similar materials to those for which the relationships were derived, the performance can be reasonably well predicted. However, as conditions change, a need exists for a rational approach. Concrete generally contains numerous flaws, such as holes or air pockets, pre-cracked aggregates, lack of bond between aggregate and matrix, etc. from

*For correspondence 
which cracking may originate. The words 'crack' and 'flaw' tend to be used interchangeably. But, while all cracks can be considered flaws, all flaws cannot be considered as cracks. The distinction is the sharpness of the crack tip, a crack being with a very small radius of curvature. When the tensile strength of a material is reached in a structure, cracking will occur. During fatigue cyclic loading, the flaw is blunted and re-sharpened and it is reasonable to assume that the crack so formed will be the nucleus of crack propagation that may lead to failure and that the crack will initiate after the first loading cycle. Cracks generally propagate in a direction, which is perpendicular to the maximum tensile stress. In heterogeneous materials, crack tends to follow the weakest path in the material. While the shape of the crack is likely to be highly irregular, it is expected that the irregularities will be smoothed out and the cracks will grow in a slow manner to a simple shape along which the stress intensity factor (SIF) is nearly uniform. Fracture mechanics is a rapidly developing field that has great potential for application to concrete structural design (Karihaloo 1995; Shah et al 1995; Van 1997; Bazant 1998, 2002).

For an ideally brittle material, the stress-strain curve is linearly elastic up to the maximum stress, at which point an initial flaw catastrophically propagates, leading to failure. A typical tensile stress-elongation curve for an ideally brittle material for which linear elastic fracture mechanics (LEFM) is valid is shown in figure 1a. For a quasi-brittle material like concrete, a substantial non-linearity exists before the maximum stress. The mechanisms of deformation beyond the proportional limit $f_{y}$ (refer figure $1 \mathrm{~b}$ ) are not clearly understood. Initially, randomly distributed micro-cracks are formed. At some point before the peak stress, micro-cracks begin to localize into a macro-crack that critically propagates at the peak stress. Strain softening is observed under steady-state propagation of this crack. Under a closedloop displacement-controlled testing condition, it is observed that the displacement during the post-peak stage consists of opening of the major crack accompanied by unloading of the rest of the specimen.

The fracture behaviour of concrete is greatly influenced by the Fracture Process Zone (FPZ). FPZ, defined as the zone in which the material undergoes softening damage (tearing), is quite small, in concrete and rock fracture the plastic flow is next to non-existent and the non-linear zone is almost entirely rolled by FPZ. Such materials are now commonly called quasi-brittle. The variation of the along the structure thickness or width is usually neglected. The inelastic fracture response due to the presence of FPZ may then be taken into account by a cohesive pressure acting on the crack faces. Figure 2 shows FPZ in brittle-ductile materials and quasi-brittle materials (Bazant 2002).

To model this behaviour using discrete crack fracture mechanics, it is assumed that an initial crack begins to propagate at the proportional limit $f_{y}$ and continues to propagate in a stable manner until the peak stress. When the crack extends in concrete, new crack surfaces are formed along the path of the initial crack tip. The newly formed crack surfaces may be in contact and this leads to toughening mechanisms in FPZ such as aggregate bridging. Further, they may continue to sustain some normal tensile stress that is characterized by a material tensile stress-separation relationship.

Distribution of the tensile stresses on the newly formed crack surfaces depends on the definition of FPZ ahead of the initial crack tip. If FPZ does not include the effect of microcracks ahead of the newly formed crack tip as shown in figure $3 \mathrm{a}$, the normal tensile stress gradually increases from the initial (open) crack tip and reaches the tensile strength of the material, $f_{t}$, at the end of FPZ (Bazant 1998).

It is noted that the tensile strength, $f_{t}$ is different than the conventional concrete tensile strength obtained from a regular tensile test. The former is regarded as a material fracture 


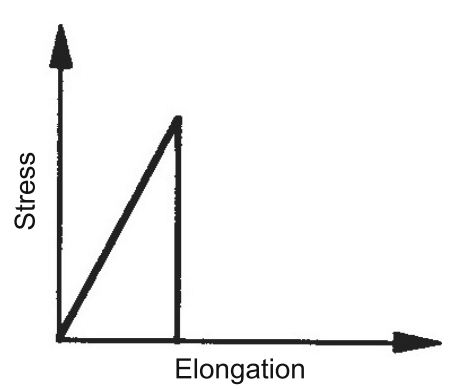

(a)

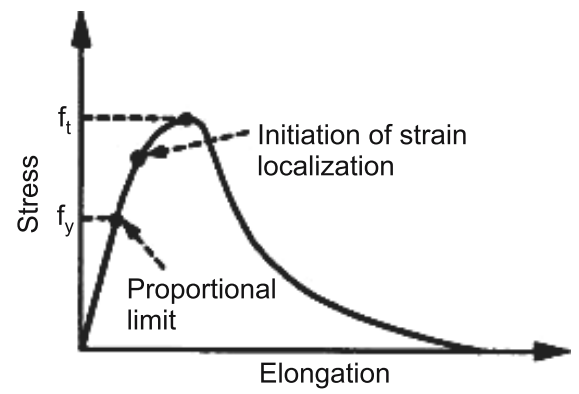

(b)

Figure 1. Tensile stress-elongation curves for (a) linear elastic material, (b) quasi-brittle material.

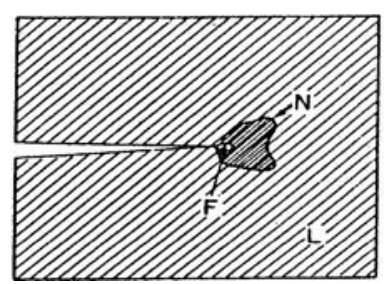

(a)

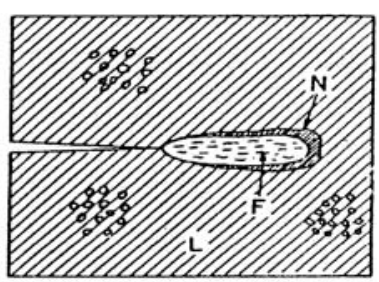

(b)
Figure 2. FPZ in brittle-ductile materials. (a) Ductile-brittle (metals), (b) Quasi-brittle (concrete).

parameter, whereas the latter depends on the material as well as the size and geometry of the tested specimen and the testing procedure. If FPZ is defined such that it includes effects of micro-cracks ahead of the newly formed crack tip as shown in figure $3 \mathrm{~b}$, the normal tensile stress gradually increases from the initial crack tip and reaches its maximum value (the tensile strength of the material) and drops to the proportional limit $f_{y}$ at the end of FPZ, as shown in figure $3 \mathrm{~b}$, where the proportional limit $f_{y}$ corresponds to initiation of micro-cracks in the material.

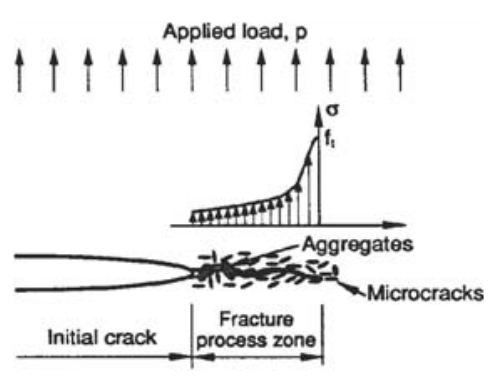

(a)

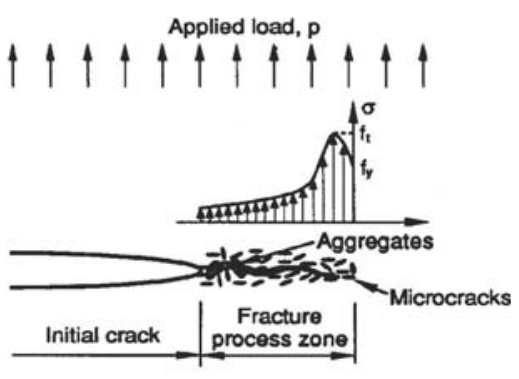

(b)

Figure 3. Concrete crack and: (a) not including effect of crack-tip micro-cracks, and (b) including effect of crack-tip micro-cracks. 


\section{Fracture mechanics of brittle materials: A critical review}

Coulomb (1776) pioneered investigation of the fracture of stones in compression. Galilei (1638) investigated the influence of size in fracture of structures. The original concept of fracture energy was conceived by Griffith (1920). Griffith theory predicted that compressive strength of a material is eight times greater than its tensile strength. Later Irwin (1957) provided extension of Griffth theory to an arbitrary crack and proposed the criterion for crack growth. Further, Irwin showed using Westergaard's method, the stress field in the area of the crack tip is completely determined by the quantity $\mathrm{K}$, called stress intensity factor (SIF). The first application of fracture mechanics to concrete was made by Kaplan (1961) using LEFM principles. Clintock \& Walsh (1962) introduced the concept of friction between crack faces. Barenblatt (1959) and Dugdale (1960) made the first attempt at including the cohesive forces in the crack tip region within the limits of elasticity theory. Barenblatt (1959) assumed that cohesive forces acted in a small zone near the crack ends such that the faces closed smoothly. The distribution of these forces is generally unknown. For Dugdale (1960), the distribution of the closing forces is known and constant according to an elastic-perfectly plastic material. A major advance in concrete fracture was made by Hillerborg et al (1976). Hillerborg's model (1976) includes the tension softening process zone through a fictitious crack ahead of the pre-existing crack whose lips are acted upon by closing forces such that there is no stress concentration at the tip of this extended crack. Kesler et al (1972) showed that the classical LEFM of sharp cracks was inadequate for normal concrete structure and this conclusion was supported by the results of Walsh $(1972,1976)$ who tested geometrically similar notched beams of different sizes. Inspired by the softening and plastic models of FPZ initiated in the works of Barenblatt (1959) and Dugdale (1960) and the models for materials other than concrete was developed by Rice (1968), Smith (1974), Knauss (1973, 1974), Wnuk (1974), Palmer \& Rice (1973) and Kfouri \& Rice (1977). Bazant (1976) and Bazant \& Cedolin (1979) used a smeared crack model to model cracking in concrete. In this model, the crack front is assumed to consist of a diffuse zone of micro-cracks and the stresses that close FPZ faces are represented through a stress-strain softening law. Hillerborg et al (1976) introduced the concept of a characteristic length, which is a unique material property. Carpinteri (1980) proposed a parameter's' as measure of concrete structural brittleness but later introduced the energy brittleness number. Extensive research work was carried out towards numerical modelling of fracture and size effect in plain concrete using lattice model (Hrennikoff 1941; Roelfstra et al 1985; Burt \& Dougill 1977; Herrman et al 1989; Herrman 1991; Schlangen \& Van 1991; 1992; Raghuprasad et al 1994; Ince et al 2003; Arslan et al 2002; Karihaloo et al 2003).

The concept of lattice model is discretization of the continuum by line elements such as bar and beam elements, which can transfer forces and moments. The advantage with lattice model is the heterogeneity of the material can be modelled/represented by assigning different strength and/or stiffness values to the individual lattice members. Another advantage with this model is that it is possible to identify micro cracking, crack branching, crack tortuosity and bridging.

Hillerborg $(1983,1985)$ improved the cohesive crack model and adapted to concrete. The finite element analysis showed that the cohesive crack model (also called the fictitious crack model) predicts, for the flexural failure of unnotched plain concrete beams, a deterministic size effect, different from the Weibull statistical size effect. This conclusion was strengthened and the model was further refined by Petersson (1981). Lange et al (1993) quantified the texture of fracture surfaces using image analysis techniques to compute a roughness parameter 
and fractal dimension. A positive correlation between fracture surface roughness and fracture toughness was demonstrated. Sundara Raja Iyengar et al (1996) applied the fictitious crack method to determine the load deflection diagrams of notched plain concrete beam under three point bending using various forms of strain softening in the stress-deformation relationship and indicated that there is a need to determine a more realistic relationship.

An analytical study of the size effect due to localization of distributed cracking was begun in 1976. Later, a simple formula for the size effect, which describes the size effect for quasibrittle failures preceded by large stable crack growth and allows determination of material fracture parameters from maximum load tests, was derived by Bazant $(1983,1984)$. The crack band model proposed by Bazant $(1982,1983)$, provides an almost equivalent alternative to the cohesive crack model. Bazant size effect law (1984) gives a measure of the brittleness of concrete elements. This model was shown to be in good agreement with the basic fracture data and size effect data and has been found to be convenient for programming (Bazant 1984; Bazant \& Schell 1993; Bazant \& Kazemi 1990). Nallathambi et al (1985) conducted experiments to study the influence of pre-crack, aggregate and specimen sizes on the fracture of concrete. A simple formula based on the experimental data was proposed to account for all the three size dependent effects. Bazant \& Sun (1987) improved the size effect formula for diagonal shear. The improvement was in two aspects, namely, the effect of maximum aggregate size distinct from the effect of the relative beam size and to cover the effect of stirr-ups on the shear capacity of concrete. Bazant (1996) discussed three methods of fracture testing in the perspective of the size effect including the merits and limitations.

Appa Rao \& Raghu Prasad (2002a) investigated the fracture properties of high strength concrete. It was observed that concrete becomes brittle with increase in compressive strength. Further, it was noted that fracture energy increases as the maximum size of coarse aggregate and compressive strength of concrete increases. Appa Rao \& Raghu Prasad (2002b) conducted experiments to investigate the bond strength of the interface between mortar and aggregate. It was observed that the bond strength of the interface in tension is significantly low, though the mortars exhibited higher strength. The bond strength of the interface in shear (mode III) significantly increases as the roughness and phase angle of the aggregate surface increase. Bazant \& Yavari (2005) examined the theories on size effect, namely, energetic statistical scaling and fractal geometry. The advantages and disadvantages in modelling the structural size effect by fractals are discussed. Emphasis was made on design aspect and codal provisions considering the size effect. Ragu Prasad \& Renuka Devi (2007) proposed a modified fictitious crack model for plain concrete beam with vertical tortuous crack and analysed the effect of tortuousity of the cracks on various fracture parameters. Carpinteri et al (2008) introduced finite fracture mechanics criterion and applied to structures with sharp V-notches. It was found that the predicted values are in good agreement with the experimental results.

When the structural components are subjected to repetitive live loads of high-stress amplitude, according to classical theory, applied loads result in in-plane tensile stresses at the bottom of the components. The stress-state in such structures is often simulated with threepoint bending tests. Plain concrete subjected to flexural loading fails owing to crack propagation. Repeated loading results in a steady decrease in the stiffness of the structure, eventually leading to failure. It is of interest to characterize the material behaviour subjected to such loading and study the crack propagation and remaining life resulting from such loading. The current approaches used to evaluate fatigue performance are mainly empirical. Fatigue equations based on the well known S-N concept have been developed. Implementation of the conventional S-N approach requires time-consuming experimental data collection for a given design case followed by statistical analysis. The resulting information is not applicable 
to other design cases with different loading configurations or boundary conditions. A severe limitation of the S-N approach is the inherent empiricism. The approach does not use fundamental material parameters that can be determined for use in design or evaluation. Mechanistic approaches that utilize the concept of fracture mechanics to study crack propagation from fatigue loading have also been proposed. For example, Perdikaris \& Calomino (1987) showed that compliance measurements provide a convenient method for estimating the traction-free crack length of fatigued concrete specimens. Since then, many experimental investigations on fatigue crack propagation in concrete have been reported (Baluch et al 1987; Ramsamooj 1994; Stuart 1982; Subramaniam et al 2000; Takashi et al 1999; Toumi \& Turatsinze 1998; Slowik et al 1996; Bazant \& Xu 1991).

The rate of fatigue crack growth in concrete exhibits an acceleration stage that follows an initial deceleration stage. In the deceleration stage the rate of crack growth decreases with increasing crack length, whereas in the acceleration stage there is a steady increase in crack growth rate up to failure. They (Baluch et al 1987; Ramsamooj 1994; Stuart 1982; Subramaniam et al 2000; Takashi et al 1999; Toumi \& Turatsinze, 1998; Slowik et al 1996; Bazant \& Xu 1991) have attempted to apply the fracture mechanics principles to describe the crack growth during the acceleration stage of fatigue crack growth in concrete. It has been observed that the Paris law coefficients are dependent on the material composition potentially explaining the large differences in the values of the Paris law coefficients. From literature, it has also been observed that the research work towards crack growth analysis and remaining life prediction of concrete structural components considering tension softening is limited.

This paper presents a critical review of literature on fracture analysis of concrete structural components. Review includes various fracture models, tension softening models, crack growth analysis, and remaining life prediction. The widely used fracture models which are based on fictitious crack approach and effective elastic crack approach have been explained. Various tension softening models such as linear, bi-linear, tri-linear etc. have been presented with appropriate expressions. Studies have been conducted on crack growth analysis and remaining life prediction using linear elastic fracture mechanics principles. Observations from remaining life prediction studies have been highlighted. Directions for further research in this area have been discussed.

\section{Nonlinear fracture mechanics for mode I quasi-brittle material}

It is known that the fracture behaviour of concrete is greatly influenced by FPZ. An effective quasi-brittle crack is shown in figure 4(a), where an initial crack and the associated FPZ are presented by a crack with length 'a' (Shah et al 1995). The toughening mechanisms in FPZ are modelled by a cohesive pressure acting on the crack surfaces as described by Jenq \& Shah (1985). The cohesive pressure $\sigma(\mathrm{w})$ is a monotonic decreasing function of crack opening displacement $w$. The value of $\sigma(w)$ is equal to material tensile strength, $f_{t}$ for $w=0$ at the crack 'tip' (the end of FPZ). This implies that micro-cracks ahead of the crack tip are not included in FPZ.

When a concrete structure with a quasi-brittle crack is subjected to loading, the applied load results in an energy release rate, $G_{q}$ at the tip of the effective quasi-brittle crack, where the subscript q stands for quasi-brittle materials. The energy release rate $G_{q}$ may be divided into two portions: (i) the energy rate consumed during material fracturing in creating two surfaces, $G_{I c}$, which is equivalent to the material surface energy, and (ii) the energy rate to overcome the cohesive pressure $\sigma(w)$ in separating the surfaces, $G_{\sigma}$, where the subscript $\sigma$ 


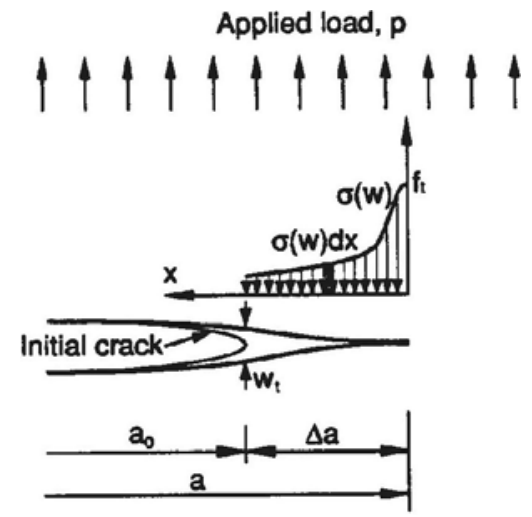

(a)

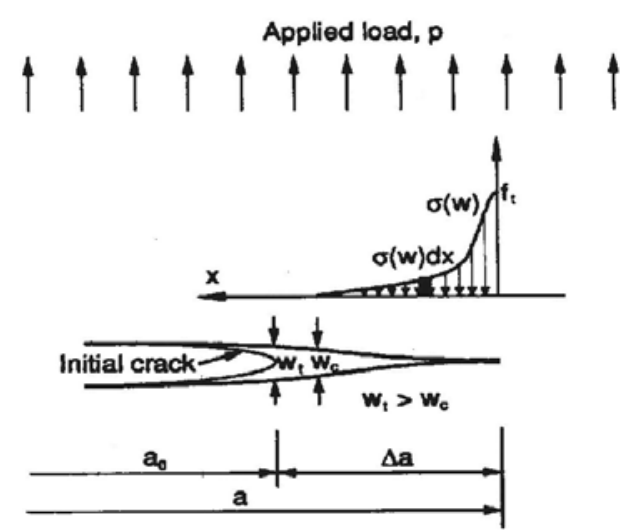

(b)

Figure 4. Modelling of quasi-brittle crack: (a) cohesive crack with crack surfaces in contact and (b) partially separated crack surfaces.

indicates this part of energy overcomes the cohesive pressure $\sigma(w)$ to open the crack. As a result, the energy release rate for a mode I quasi-brittle crack, $G_{q}$, can be expressed as

$$
G_{q}=G_{I c}+G_{\sigma}
$$

The value of $G_{I c}$, can be evaluated based on LEFM and is called the critical energy release rate. Since $G_{\sigma}$ is equal to the work done by the cohesive pressure over a unit length of the crack for a structure with a unit thickness, its value can be calculated using the following expression

$$
G_{\sigma}=\frac{1}{\Delta a} \int_{0}^{\Delta a} \int_{0}^{w} \sigma(w) d x d w=\frac{1}{\Delta a} \int_{0}^{\Delta a} d x \int_{0}^{w} \sigma(w) d w=\int_{0}^{w} t \sigma(w) d w
$$

where $\sigma(w)$ is the normal cohesive pressure and $w_{t}$ is the crack separation displacement at the initial crack tip, as shown in figure 4(a). Substituting (2) into (1) leads to

$$
G_{q}=G_{I c}+\int_{0}^{W_{t}} \sigma(w) d w .
$$

It can be observed that when $w_{t}>w_{c}$ as shown in figure 4(b), the upper integral limit $w_{t}$ in (3) should be replaced by $w_{c}$. Equation (3) indicates that for quasi-brittle fracturing, the energy release rate due to the applied load $G_{q}$ is balanced by two fracture energy dissipation mechanisms. The Griffith-Irwin energy dissipation mechanism is represented by the fracture energy release rate $G_{I c}$, whereas the Dugdale-Barenblatt energy dissipation mechanism is represented by the material traction term $G_{\sigma}$.

\subsection{Concrete fracture models}

Based on different energy dissipation mechanisms used, non-linear fracture mechanics models for quasi-brittle materials can be classified as a fictitious crack approach and an equivalentelastic crack approach (or an effective-elastic crack approach). Fracture mechanics models 
using only the Dugdale-Barenblatt energy dissipation mechanism are usually referred to as the fictitious crack approach, whereas fracture mechanics models using only the Griffth-Irwin energy dissipation mechanism are usually referred to as the effective-elastic crack approach or equivalent elastic crack approach. Brief description of various models based on fictitious crack approach as well as effective-elastic crack approach is described in table 1.

\section{Tension softening models}

It is known that the cohesive crack model requires a unique $\sigma(w)$ curve to quantify the value of energy dissipation. The choice of the $\sigma(w)$ function influences the prediction of the structural response significantly, and the local fracture behaviour, for example the crack opening displacement, is particularly sensitive to the shape of $\sigma(w)$. Many different shapes $\sigma(w)$ curves, including linear, bilinear, trilinear, exponential, and power functions, have been previously used. Some of the widely used $\sigma(w)$ curves are listed in table 2.

The CEB-FIP Model Code (1990) also recommended a bilinear curve for $\sigma(w)$. However, the value of $w_{c}$ depends on maximum aggregate size $d_{a}$. The value of $\sigma_{1}$ was assigned to be equal to $0 \cdot 15 f_{t}$ and the value of $w_{1}$ in units of millimeters is given by

$$
w_{1}=\frac{G_{F}-22 w_{c}\left(G_{F} / k_{d}\right)^{0 \cdot 95}}{150\left(G_{F} / k_{d}\right)^{0 \cdot 95}},
$$

where the coefficient $k_{d}$ also depends on the maximum aggregate size $d_{a}$. In the absence of test data, CEB-FIP Model Code also specifies empirical relations for the fracture parameters of the fictitious crack model in terms of the mean compressive strength $f_{c}$ :

$$
f_{t}=0 \cdot 3\left(f_{c}+8\right)^{2 / 3}, G_{F}=k_{d} f_{c}^{0 \cdot 7}, E=10^{4} f_{c}^{1 / 3},
$$

in which $f_{c}, f_{t}$, and $E$ are in megapascals and $G_{F}$ is in newtons per meter.

Since the assessment of the fracture behavior of a concrete structure is influenced by using different $\sigma(w)$ functions, reasonable and accurate determinations of the $\sigma(w)$ curve and the corresponding parameters become crucial for the cohesive crack approach. Experimental determination of $\sigma(w)$ directly from tension tests has been suggested by Gopalaratnam and shah (1985), but this is difficult and the results may vary with specimen size and shape. Li et al (1987) have proposed a J-integral-based method for obtaining the entire $\sigma(w)$ curve. Miller et al (1991) have computed the $\sigma(w)$ curve from parabolic crack profiles observed in fracture tests through laser holography interferometry. Yon et al (1997) and Du et al (1990) have applied Moire interferometry to deduce crack profiles that were used to determine the stress-opening relation in the process zone.

From the critical review of models, it can be observed that the models are subjective in view of the following reasons:

- Some of the models are complex and do not readily lend themselves to mathematical manipulation such as differentiation and integration.

- Number of models are divided into two separate expressions hence adding to the complexity of the model.

- Some of the models require parameters obtained through curve fitting methods

There is scope and need to develop more generalised models to represent realistic closing pressure distribution. 


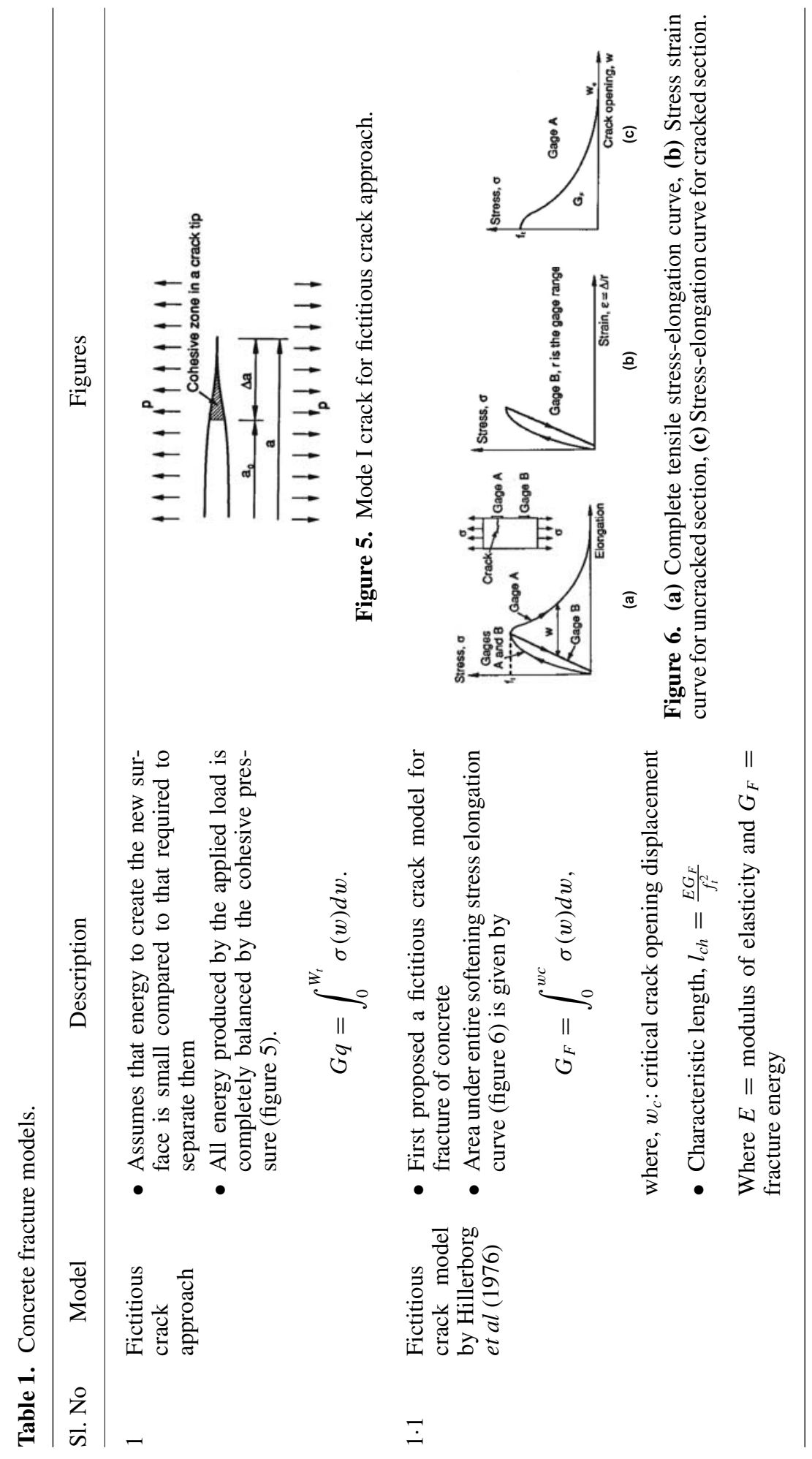




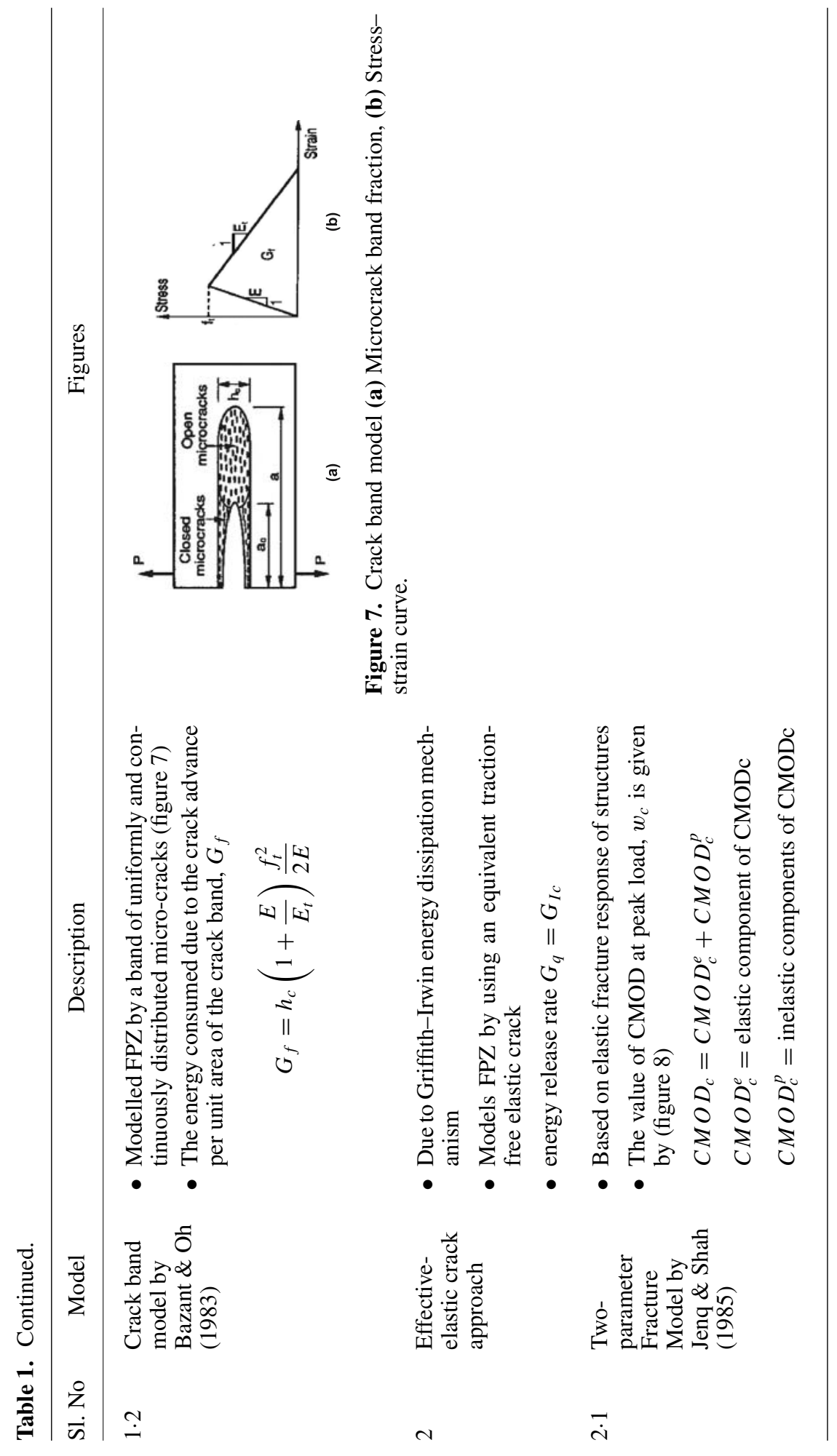




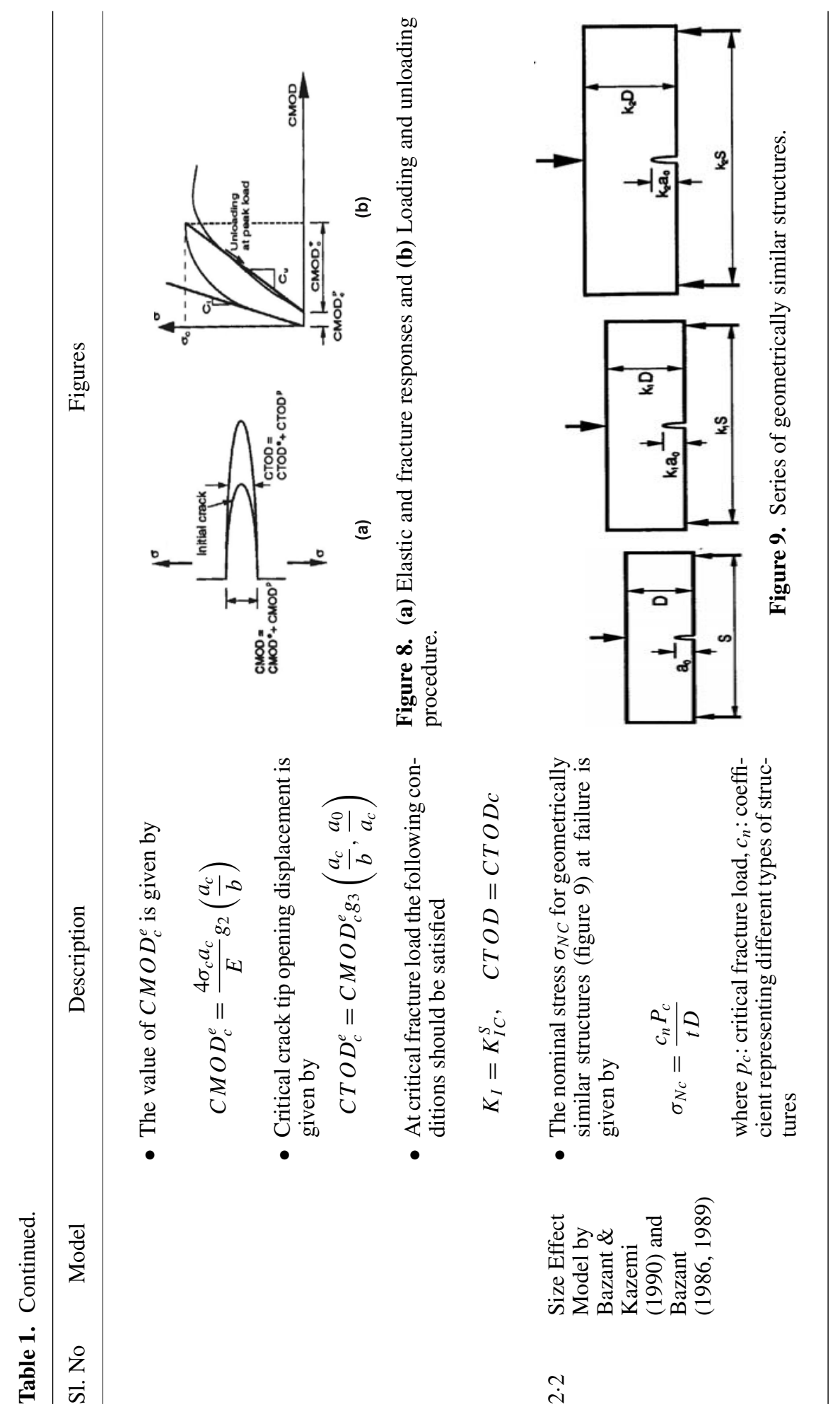




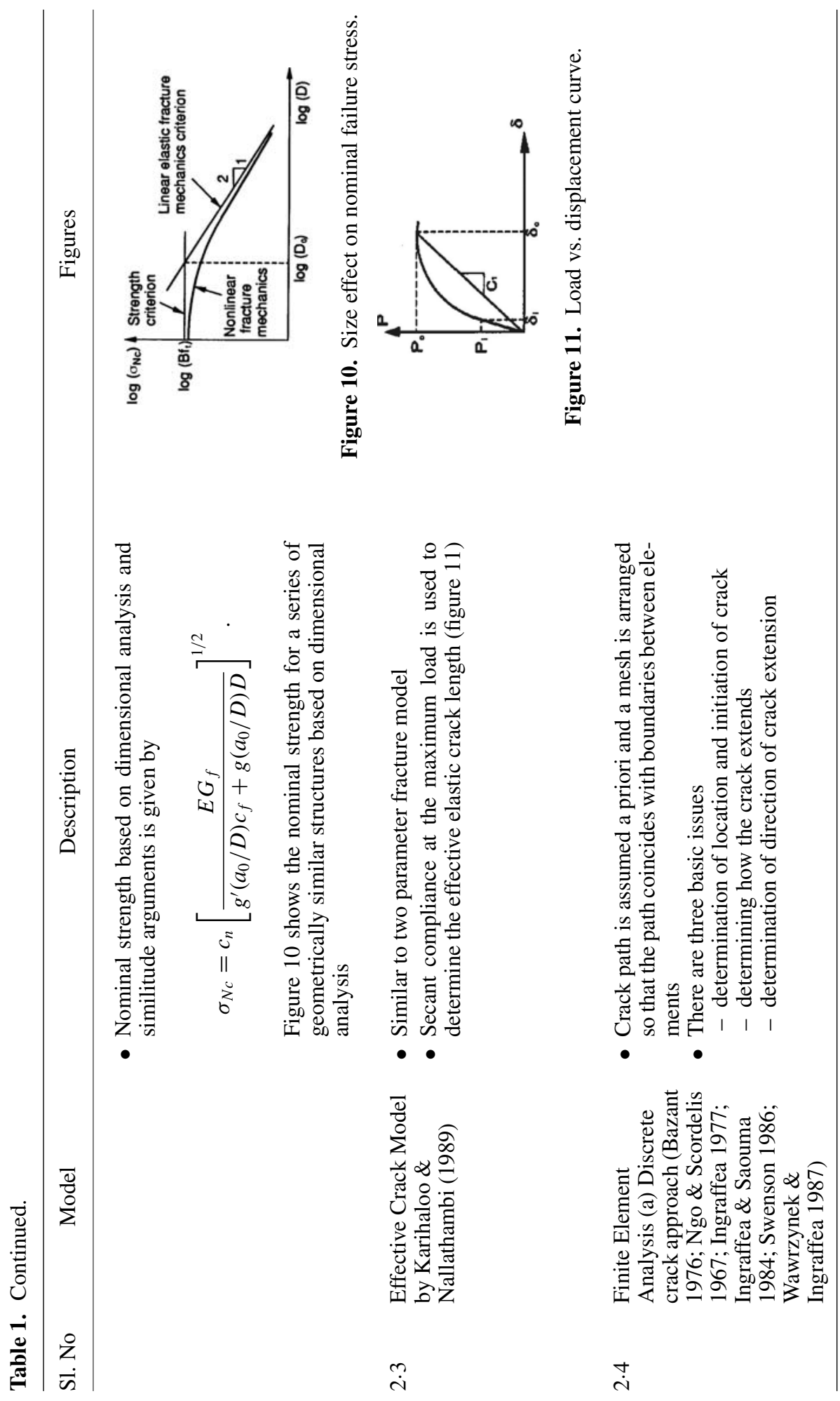




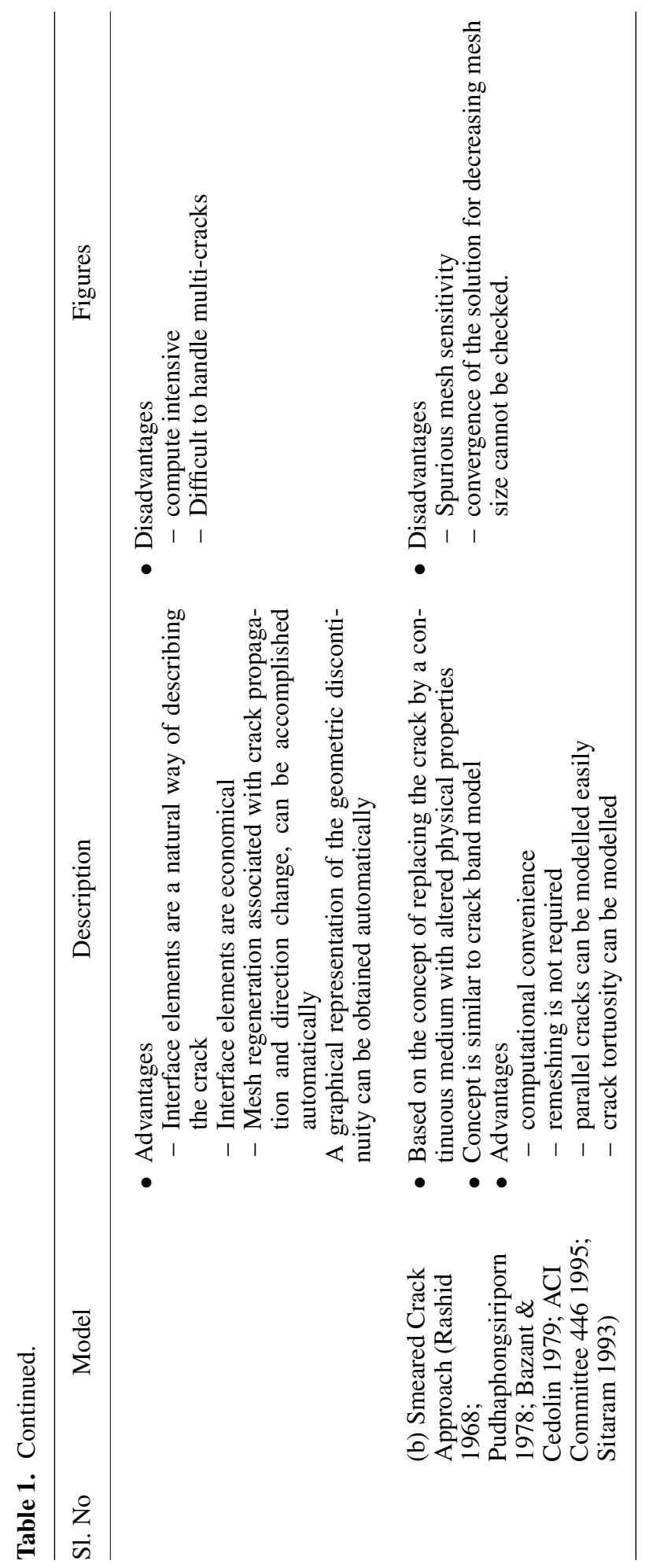


Table 2. Different types of closing pressure for FPZ.

\begin{tabular}{lcl}
\hline Type & Expression & Shape \\
\hline $\begin{array}{l}\text { Linear curve } \\
\text { (Hillerborg } \\
\text { et al 1976) }\end{array}$ & $\sigma=f_{t}\left(1-w / w_{c}\right)$ \\
$\longrightarrow \mathrm{w}$
\end{tabular}
$\begin{aligned} & \text { Bilinear curve } \\ & \text { Roelfstra \& }\end{aligned} \quad \sigma= \begin{cases}f_{t}-\left(f_{t}-\sigma_{1}\right) w / w_{1} & \text { for } w \leq w_{1} \\ \sigma_{1}-\sigma_{1}\left(w-w_{1}\right) /\left(w_{c}-w_{1}\right) & \text { for } w_{1}>w\end{cases}$ Wittmann

1986)

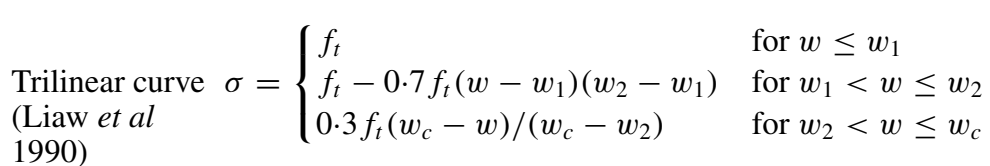

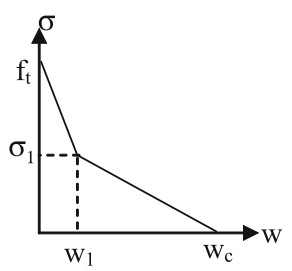

Exponential curve (Footer et al 1986)

(Reinhardt 1985)

Gopalaratnam \& Shah (1985) similar relationship was also suggested by Cedolin et al (1987)

Power curve (Du et al 1990)

$$
\sigma=f_{t}\left(1-\frac{w}{w_{c}}\right)^{n}
$$

where $n$ is a fitting parameter

$$
\sigma=f_{t}\left\{1-\left(\frac{w}{w_{c}}\right)^{n}\right\}
$$

where $0<n<1$ is a fitting parameter
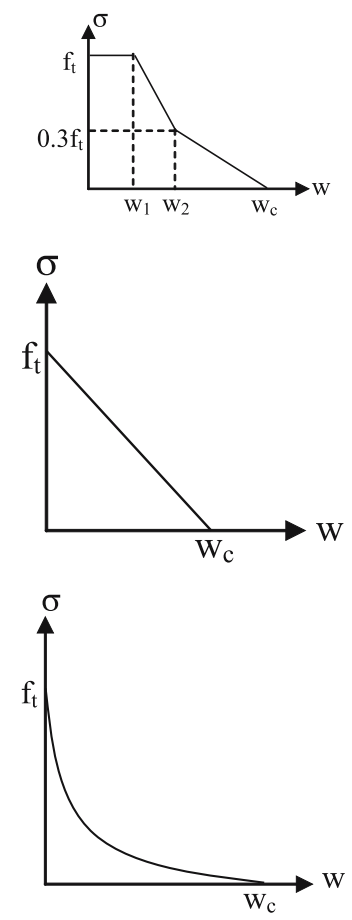

where $k$ and $\lambda$ are material parameters $k=-0.06163$ and $\lambda=1.01$ for concrete with $f_{c}^{\prime}$ values of 33-47 MPa.

$$
\sigma=f_{t} \exp \left(k w^{\lambda}\right)
$$

$$
\sigma=0.4 f_{t}\left(1-w / w_{c}\right)^{1 \cdot 5}
$$


Table 2. Continued.

\begin{tabular}{lc}
\hline Type & Expression \\
$\begin{array}{l}\text { Bilinear curve } \\
\text { with } w_{1}=0 \\
\text { (Figueiras \& } \\
\text { Owen 1984) }\end{array}$ & where $k=a$ constant \\
& $\sigma=f_{c}\left\{\left[1-w / w_{c}\right)\right.$ \\
$\begin{array}{l}\text { Power curve } \\
\text { (Hordijk 1991) }\end{array}$ & $\left.-\frac{w}{w_{c}}\left(1+a_{1}^{3}\right) \exp \left(-a_{2}\right)\right\}$ \\
& where $a_{1}$ and $a_{2}$ are fitting parameters
\end{tabular}

\section{Numerical studies}

Numerical studies have been conducted on remaining life prediction of concrete structural components. Section $5 \cdot 1$ presents the details of remaining life prediction studies using LEFM principles.

\subsection{Remaining life prediction using LEFM}

Crack growth studies and remaining life prediction has been carried out for concrete threepoint bending specimens under constant amplitude loading. The details of the studies are presented below.

5.1a Problem 1: This problem was studied by Toumi \& Turatsinze (1998) for three-point bending concrete specimen (figure 12).

Length $(\mathrm{S})=320 \mathrm{~mm}$

Depth $(\mathrm{b})=80 \mathrm{~mm}$

Thickness $(\mathrm{t})=50 \mathrm{~mm}$

Initial crack length $\left(a_{o}\right)=2$ to $4 \mathrm{~mm}$

Compressive strength $=57 \mathrm{MPa}$

Tensile strength $=4.2 \mathrm{MPa}$

Fracture toughness $=0.63 \mathrm{MPa} \sqrt{ } \mathrm{m}$

Crack growth equation $=$ Paris

Min. load $=198.72 \mathrm{~N}$

The bending tensile stress $\left(f_{b}\right)$ can be calculated by using the formula given below

$$
f_{b}=3 P l / 2 t b^{2} \text {. }
$$


Table 3. Predicted remaining life values.

\begin{tabular}{|c|c|c|c|c|c|c|}
\hline \multirow[b]{2}{*}{ S. No. } & \multirow{2}{*}{$\begin{array}{l}\text { Max. } \\
\text { Stress } \\
(\mathrm{MPa})\end{array}$} & \multicolumn{2}{|c|}{ Crack growth constants } & \multicolumn{2}{|c|}{ Remaining life (Cycles) } & \multirow[b]{2}{*}{$\%$ diff. } \\
\hline & & $\begin{array}{c}\mathrm{C} \\
(\mu \mathrm{m} / \text { cycle })\end{array}$ & $\mathrm{m}$ & $\begin{array}{l}\text { Present } \\
\text { study }\end{array}$ & $\begin{array}{c}\text { Toumi \& Turatsinze } \\
1998 \text { (Exptl.) }\end{array}$ & \\
\hline 1 & $1 \cdot 125$ & $6 \cdot 45$ & $4 \cdot 18$ & 28689 & 32222 & $10 \cdot 96$ \\
\hline 2 & 1.05 & $0 \cdot 33$ & $2 \cdot 31$ & 57251 & 63611 & 9.99 \\
\hline 3 & $0 \cdot 975$ & $0 \cdot 26$ & $2 \cdot 25$ & 62603 & 69444 & $9 \cdot 85$ \\
\hline 4 & $0 \cdot 9$ & $2 \cdot 04$ & $2 \cdot 6$ & 16188 & 18333 & $11 \cdot 71$ \\
\hline
\end{tabular}

Crack growth analysis and remaining life prediction has been carried out for various loadings using corresponding crack growth constants. Remaining life has been predicted for the different loading cases using LEFM Principles. Geometric factor has been calculated by using the expression given below (Tada et al 1985).

$$
g_{1}\left(\frac{a}{b}\right)=\frac{1 \cdot 0-2 \cdot 5 a / b+4 \cdot 49(a / b)^{2}-3 \cdot 98(a / b)^{3}+1 \cdot 33(a / b)^{4}}{(1-a / b)^{3 / 2}} .
$$

Table 3 shows the predicted remaining life values for the above cases along with the experimental values presented by Toumi \& Turatsinze (1998). From table 3, it can be observed that there is about $12 \%$ difference between the predicted and experimental observations. The difference in the values can be attributed to not considering the tension softening effect in the analysis. Figure 13 shows the variation of predicted remaining life with crack length for various loading cases.

5.1b Problem 2: Another example problem has been chosen for crack growth study and remaining life prediction. This problem was studied earlier by Baluch et al (1987).

Length of supported span (s) $=1360 \mathrm{~mm}$

Thickness $(\mathrm{t})=51 \mathrm{~mm}$

Depth $(b)=152 \mathrm{~mm}$ Fracture toughness $=1.16 \times 10^{6} \mathrm{~N} / \mathrm{m}^{3 / 2}$

Other input details are shown in table 4. Table 4 shows the predicted remaining life for different loading cases. From table 4, it can be observed that there is about $11 \%$ difference between the predicted value and the corresponding experimental observation.

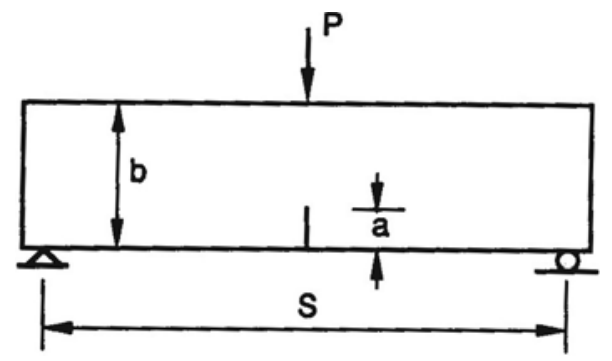

Figure 12. Three point bending problem. 


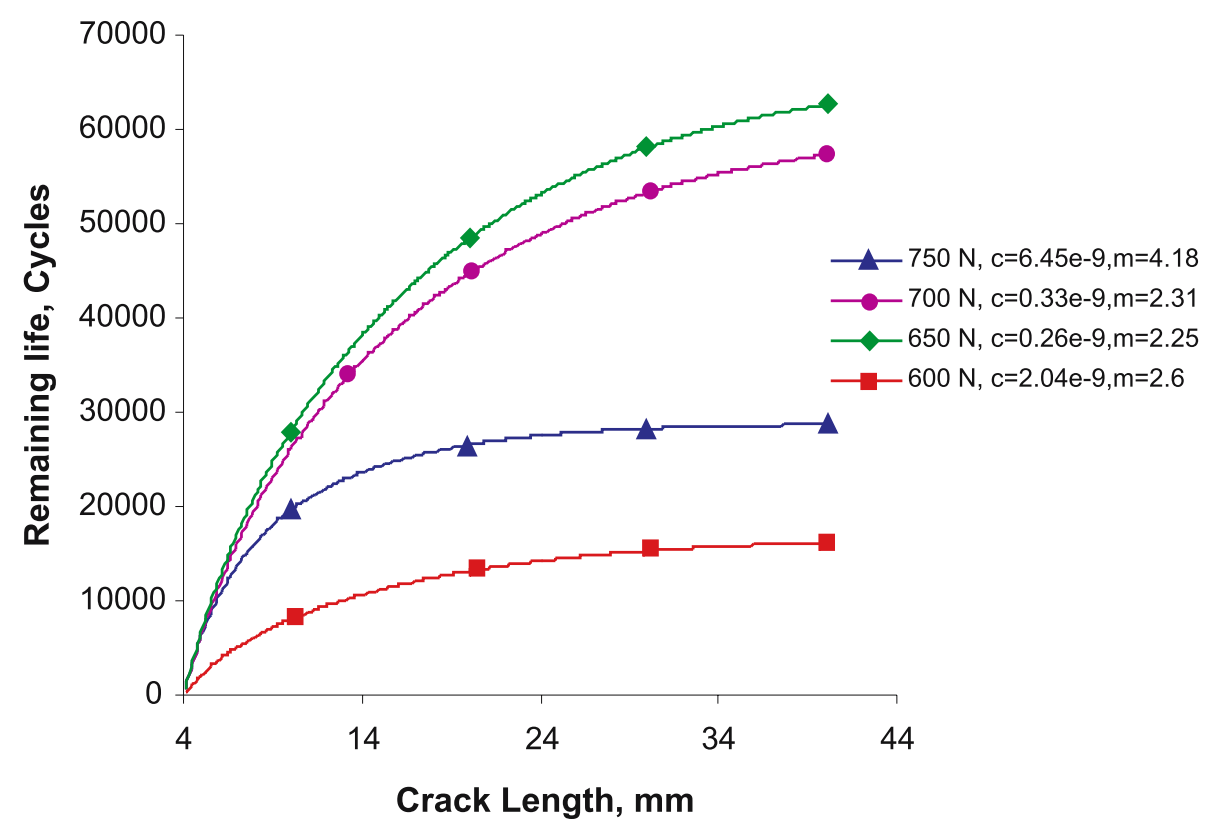

Figure 13. Crack length vs. remaining life.

\section{Summary and concluding remarks}

A critical review of literature on fracture analysis of concrete has been carried out. Review includes various fracture models, tension softening models and methodologies for crack growth analysis and remaining life prediction. It has been observed that fracture process zone (FPZ) plays an important role in the fracture analysis of quasi-brittle materials like concrete. The widely used fracture models are based on (i) fictitious crack approach and (ii) effective elastic crack approach have been explained. Fictitious crack approach model uses the Dugdale-Barenblatt energy dissipation mechanism which assumes that all energy produced

Table 4. Predicted remaining life values.

\begin{tabular}{|c|c|c|c|c|c|c|}
\hline \multirow{2}{*}{$\begin{array}{l}\text { Sl. } \\
\text { No. }\end{array}$} & \multirow{2}{*}{$\begin{array}{c}\text { Max. } \\
\text { stress (MPa) }\end{array}$} & \multirow{2}{*}{$\begin{array}{l}\text { Stress } \\
\text { ratio }\end{array}$} & \multirow{2}{*}{$\begin{array}{l}\text { Initial crack } \\
\text { length, mm }\end{array}$} & \multicolumn{2}{|c|}{ Crack growth constants } & \multirow{2}{*}{$\begin{array}{c}\text { Remaining life } \\
\text { (Cycles) }\end{array}$} \\
\hline & & & & $\mathrm{C}$ & $\mathrm{m}$ & \\
\hline 1 & & $0 \cdot 1$ & & $7 \cdot 71 \mathrm{e}-25$ & $3 \cdot 12$ & $38078^{*}$ \\
\hline 2 & 0.5194 & $0 \cdot 2$ & 75 & $5 \cdot 78 \mathrm{e}-24$ & $3 \cdot 12$ & 33176 \\
\hline 3 & & $0 \cdot 3$ & & $1.72 \mathrm{e}-24$ & $3 \cdot 15$ & 25436 \\
\hline 4 & & $0 \cdot 1$ & & $7 \cdot 71 \mathrm{e}-25$ & $3 \cdot 12$ & 24536 \\
\hline 5 & 0.692 & $0 \cdot 2$ & 75 & $5 \cdot 78 \mathrm{e}-24$ & $3 \cdot 12$ & 21987 \\
\hline 6 & & $0 \cdot 3$ & & $1.72 \mathrm{e}-24$ & $3 \cdot 15$ & 14789 \\
\hline 7 & & $0 \cdot 1$ & & $7 \cdot 71 \mathrm{e}-25$ & $3 \cdot 12$ & 25123 \\
\hline 8 & 0.4328 & $0 \cdot 2$ & 85 & $5 \cdot 78 \mathrm{e}-24$ & $3 \cdot 12$ & 22453 \\
\hline 9 & & $0 \cdot 3$ & & $1.72 \mathrm{e}-24$ & $3 \cdot 15$ & 17936 \\
\hline
\end{tabular}

*-Experimental value 44000 
by the applied load is completely balanced by the cohesive pressure. The fictitious crack is assumed to initiate and propagate when the principal tensile stress reaches the tensile strength of the material. Effective elastic crack approach uses the Griffith-Irwin energy dissipation mechanism. The effective elastic crack approach models FPZ by using an equivalent tractionfree elastic crack.

Various tension softening models such as linear, bi-linear, tri-linear, etc. have been presented with appropriate expressions. From the critical review of models, it has been observed that the models are subjective in view of the following reasons:

- Some of the models are complex and do not readily lend themselves to mathematical manipulation such as differentiation and integration

- Number of models are divided into two separate expressions hence adding to the complexity of the model

- Some of the models require parameters obtained through curve fitting methods.

There is scope and need to develop more generalised models to represent closing pressure distribution.

Studies have also been conducted on crack growth analysis and remaining life prediction using LEFM principles. From the studies, it has been observed that there is about $12 \%$ difference between predicted and experimental observations. The difference in the values can be attributed to not considering the tension softening effect in the analysis. For reliable remaining life prediction, effect of tension softening should be considered appropriately in the analysis by employing NLFM principles.

Authors thank their colleagues Mr J Rajasankar, Asst. Director and Ms. Smitha Gopinath for their technical support, discussions and suggestions during the coarse of investigation. This paper is being published with the kind permission of the Director, Structural Engineering Research Centre (SERC), Chennai, India.

\section{List of symbols}

$\begin{array}{ll}f_{t} & \text { Tensile strength of the material } \\ f_{y} & \text { Yield strength of the material } \\ \sigma(w) & \text { Cohesive pressure } \\ w & \text { Crack opening displacement } \\ w_{c} & \text { Critical crack opening displacement } \\ G_{q} & \text { Energy release rate } \\ G_{I c} & \text { Critical energy release rate } \\ G_{\sigma} & \text { Work done by the cohesive pressure } \\ w_{t} & \text { Crack separation displacement } \\ E & \text { Modulus of elasticity } \\ G_{F} & \text { Fracture energy } \\ C M O D_{c} & \text { Critical crack mouth opening displacement } \\ C M O D_{c}^{e} & \text { Elastic component of } C M O D_{c} \\ C M O D_{c}^{p} & \text { In elastic component of } C M O D_{c} \\ \sigma_{c} & \text { Critical stress } \\ a_{c} & \text { Critical crack length }\end{array}$




$\begin{array}{ll}g_{2}\left(\frac{a_{c}}{b}\right) & \text { Geometry factor for CMOD } \\ C T O D_{c}^{e} & \text { Critical crack tip opening displacement } \\ g_{3}\left(\frac{a_{c}}{b}, \frac{a_{0}}{a_{c}}\right) & \text { Geometry factor for CTOD } \\ K_{I} & \text { Stress intensity factor (SIF) for mode I } \\ K_{I C}^{S} & \text { Critical SIF for mode I } \\ \sigma_{N C} & \text { Nominal stress } \\ P_{c} & \text { Critical fracture load } \\ c_{n} & \text { Coefficient representing different types of structures } \\ D & \text { Depth of the beam } \\ f_{c} & \text { Compressive strength of concrete } \\ f_{b} & \text { Tensile bending stress } \\ l & \text { Length of the beam } \\ t & \text { thickness of the beam } \\ b & \text { width of the beam } \\ g_{1}\left(\frac{a}{b}\right) & \text { Geometry factor using LEFM } \\ a & \text { Crack length } \\ C, m & \text { Paris crack growth constants }\end{array}$

\section{References}

Abdalla H M, Karihaloo B L 2004 A method for constructing the bilinear tension softening diagram of concrete corresponding to its true fracture energy. Magazine of Concrete Res. 56(10): 597-604

ACI Committee 4461995 Finite Element Analysis of Fracture in Concrete Structures. Report of Subcommittee 3, (Detroit: American Concrete Institute)

Appa Rao G, Raghu Prasad B K 2002a Fracture energy and softening behavior of high-strength concrete. Cement and Concrete Res. 32: 247-252

Appa Rao G, Raghu Prasad B K 2002b Influence of the roughness of aggregate surface on the interface bond strength. Cement and Concrete Res. 32: 253-257

Arslan A, Ince R, Karihaloo B L 2002 Improved lattice model for concrete fracture. J. Eng. Mech. ASCE 128: 57-65

Baluch M H, Qureshy A B, Azad A K 1987 Fatigue crack propagation in plain concrete. S P Shah, S E Swartz (eds.) SEM/RILEM Int. Conf. on Fracture of Concrete and Rock, Houston, 80-87

Barenblatt G I 1959 Equilibrium cracks formed during brittle fracture. Prikl. Mat. Mech 23

Bazant Z P 1976 Instability, Ductility and size effect in strain-softening concrete. J. Engg. Mech. ASCE 102: 331-344

Bazant Z P 1982 Crack band model for fracture of geomaterials. Eisenstein Z (ed.) Proc. 4th Int. Conf. on Numerical Methods in Geomechanics, 3, Edmonton, Alberta, 1137-1152

Bazant Z P 1983 Fracture in concrete and reinforced concrete. Bazant Z P (ed.) Preprints, IUTAM Prager Symposium on Mechanics of Geomaterials, Rocks, Concretes, Soils, North Western University, Evanston, 281-316

Bazant Z P 1984 Size effect in blunt fracture: Concrete, Rock, Metal. J. Eng. Mech. ASCE 110(4): $518-535$

Bazant Z P 1986 Fracture mechanics and strain-softening in concrete. Proceedings of U.S.-Japan Seminar on Finite Element Analysis of Reinforced Concrete Structures, ASCE, New York 121-150

Bazant Z P 1989 Fracture energy of heterogeneous materials and similitude. In Fracture of Concrete and Rock, S P Shah, S E Swartz (eds.) (New York: Springer-Verlag) 229-241

Bazant ZP 1996 Size effect aspects of measurement of fracture characteristics of quasi-brittle material. Advanced Cement Based Materials 129(4): 128-137

Bazant Z P 1998 Fracture and Size Effect in Concrete and other quasi Brittle Materials, CRC Press 
Bazant Z P 2002 Concrete fracture model: testing and practice. Eng. Fract. Mech. 69: 165-205

Bazant Z P, Cedolin L 1979 Blunt crack bond propagation in finite element analysis. J. Eng. Mech. ASCE 105(2) 297-315

Bazant Z P, Kazemi M T 1990 Determination of fracture energy, process zone length and brittleness number from size effect, with application to rock and concrete. Int. J. Fract. 44: 111-131

Bazant Z P, Kim J K 1984 Size effect in shear failure of longitudinally reinforced beams. ACI Structural J. 81: 456-468

Bazant Z P, Oh B H 1983 Crack band theory for fracture of concrete. Materials and Structures, RILEM 16: $155-177$

Bazant Z P, Sun H H 1987 Size effect in diagonal shera failure: Influence of aggregate size and stirrups. ACI Materials J July-August 259-272

Bazant Z P, William F, Schell 1993 Fatigue fracture of high strength concrete and size effect. ACI materials J. 90(5): 472-478

Bazant Z P, Xu K 1991 Size effect in fatigue fracture of concrete. ACI Materials J. 88(4): 390-399

Bazant Z P, Yavari A 2005 Is the cause of size effect on structural strength fractal or energeticstatistical. Eng. Fract. Mech. 72: 1-31

Burt N J, Dougill J W 1977 Progressive failure in a model heterogeneous medium. J. Eng. Mech. Division-ASCE, 103: 365-376

Carpinteri A 1980 Notch sensitivity in fracture testing of aggregative materials. Istituto di scienza delle Construzioni, universita di Bologna, Nota Technia n 45. Eng. Fract. Mech. 16

Carpinteri A P, Cornetti N, Pugno A S, Taylor D 2008 A finite fracture mechanics approach to structures with sharp V-notches. Eng. Fract. Mech. 75: 1736-1752

CEB-FIP Model code 1990 Bulletind Information No. 190a, 190b, Comite Euro International du Beton (CEB), Lausanne

Cedolin L, Deipoli S, Iori I 1987 Tensile behaviour of concrete. J. Eng. Mech. ASCE 113(3): 431-449

Clintock F A, Walsh P F 1962 Friction on Griffith cracks in rocks under compression. Proc. $4^{\text {th }}$ National congress, Appl. Mech., Berkeley

Coulomb C A 1776 Remarque sur la rupture des corp. Memories presents par divers savants a 1, Academic, 7

Du J, Yon J H, Hawkins N M, Kobayashi A S 1990 Analysis of the Fracture Process Zone of a Propagating Concrete Crack Using Moire Interferometry, in Micromechanics of Failure of QuasiBrittle Materials, S P Shah, S E Swartz and M L Wang (eds.) London: Elsevier Applied Science, 146-155

Dugdale D S 1960 Yielding of steel sheets containing slits. J. Mechanics and Physics of Solids 8

Figueiras J A, Owen D R J 1984 Non-linear analysis of reinforced concrete shell structures. Intl. conf. on Computer Aided Analysis and Design of Concrete Structures, Part I, split, Yugoslavia, $509-532$

Footer M L, Mai Y W, Cotterell B 1986 Crack growth resistance curves in strain-softening materials. J. Mech. and Physics of Solids 34(6): 593-607

Galilei G 1638 Discorsi e dimostrazioni matemathiche intorno a due nuove scienze. Elzeviri, Ledia (English translation, Two sciences, New York: The Macmillan Company)

Gopalaratnam V S, Shah S P 1985 Softening response of plain concrete in direct tension. ACI Journal 82(3): $310-323$

Griffith A A 1920 The phenomena of rupture and flow in solids. Philosophical Transactions of the Royal Society of India, series A221, 1920 241-257

Herrman H J 1991 Patterns and scaling in fracture. Fracture Process in Concrete, Rock and Ceramics. JGM Van Micr J G Rots and A Bakker (eds.), (Spain, London, New York: Chapman Hall) p. 195

Herrman H J, Hansen A, Roux S 1989 Fracture of disorder elastic latticcs in two dimensions. Phys Rev B. 39: 637-648

Hillerborg A 1983 Examples of practical results achieved by means of the fictitious crack model. Z P Bazant (ed.), IUTAM, Prager Symposium on Mechanics of Geomaterials: Rocks, Concretes, Soils, Northwestern University, Evanston 611-614 
Hillerborg A 1985 The theoretical basis of method to determine the fracture energy $G_{F}$ of concrete. Mater. Struct. 18(106): 291-296

Hillerborg A, Modeer M, Petersson P E 1976 Analysis of crack formation and crack growth in concrete by means of fracture mechanics and finite elements. Cement and Concrete Res. 6: 773-782

Hordijk D A 1991 Local Approach to Fatigue of Concrete. Ph.D thesis, Technical University of Delft Hrennikoff A 1941 Solution of Problems of Elasticity by the Framework Method. J. Appl. Mech. Trans. ASME 8: A169-A175

Ince R, Arslan A, Karihaloo B L 2003 Lattice Modelling of size Effect in Concrete Strength. Eng. Fract. Mech. 170: 2307-2320

Ingraffea A R, Saouma V 1984 Numerical modelling of discrete crack propagation in reinforced and plain concrete. Fracture mechanics of concrete: Structural application and numerical calculation, by G Sih et al (eds.), Dordrecht 171-225

Ingraffea A R 1977 Discrete Fracture Propagation in Rock: Laboratory Tests and Finite Element Analysis. Ph.D. Dissertation, Univrsity of Colorado, Boulder

Irwin G R 1957 Analysis of stresses and strains near the end of a crack traversing a plate. J. Applied Mechanics, ASME, New York 24(3): 351-369

Jenq T S, Shah S P 1985 Two parameter fracture model for concrete. J. Eng. Mech. ASCE 111(4): $1227-1241$

Kaplan M E 1961 crack propagation and fracture of concrete. J. American Concrete Institute 58(5): $591-610$

Karihaloo B L, Nallathambi P 1989 An improved effective crack model for the determination of fracture toughness of concrete. Cement and Concrete Res. 19: 603-610

Karihaloo B L 1995 Fracture Mechanics and Structural Concrete, (New York: Longman Scientific Technical)

Karihaloo B L, Shao P F, Xiao O Z 2003 Lattice Modelling of the Failure of Particle Composites 170: $2385-240$

Kesler C E, Naus D J, Lott J L 1972 Fracture mechanics-its applicability to concrete. Proc. Int. Conf. on the Mechanical Behaviour of Materials, Vol. IV, Kyoto, The Society of Materials Science $113-124$

Kfouri A P, Rice J R 1977 Elastic-plastic separation energy rate for crack advance in finite growth steps, D M R Taplin (ed.), Fracture (Proceedings, 4th International Conference on Fracture, ICF4, Waterloo), vol. 1, University of Waterloo, Ontario, Canada 43-59

Knauss W C 1973 On the steady propagation of a crack in a viscoelastic sheet-experiment and analysis. H H Kausch (ed.), The deformation in fracture of high polymers, New York: Plenum 501-541

Knauss W C 1974 On the steady propagation of a crack in a viscoelastic plastic solid. J. Appl. Mech. 41(1): 234-248

Lange D A, Jennings H M, Shah S P 1993 Relationship between fracture surface roughness and fracture behavior of cement paste and mortar. J. American Ceramic Soc. 76(3): 589-597

Li V C, Chan C M, Leung C K Y 1987 Experimental determination of the tension softening relations for cementations composites. Cement and Concrete Res. 17: 441-452

Liaw B M, Jeang F L, Du J J, Hawkins N M, Kobayashi A S 1990 Improved non-linear model for concrete fracture. J. Engg. Mech. ASCE 116(2): 429-445

Miller R A, Castro Montero A, Shah S P 1991 Cohesive crack models for cement holographic measurement. J. American Ceramic Soc. 74: 130-138

Nallathambi P, Karihaloo B L, Heaton B S 1985 Various Size Effects In Fracture of Concrete. Cement and Concrete Res. 15: 117-126

Ngo D, Scordelis A C 1967 Finite Element Analysis of Reinforced Concrete Beams, ACI J. 64(3): 152-163

Palmer A C, Rice J R 1973 The growth of slip surfaces on the progressive failure of over-consolidated clay. Proc. R. Soc London A Series 332: 527-548

Perdikaris P C, Calomino 1987 Kinetics of crack growth in plain concrete. Proc. Int. conf. Fracture of concrete and Rock, Houston 96-101 
Petersson P E 1981 Crack growth and development of fracture zones in plain concrete and similar materials. Report TVBM-1006, Division of Building Materials, Lund Institute of Technology, Lund, Sweden

Pudhaphongsiriporn P 1978 An Experimental Study of a Reinforced Concrete Folded Plate Structure. Ph.D Dissertation, Purdue University, West Lafayette

Raghu Prasad B K, Renuka Devi M V 2007 Extension of FCM to plain concrete beams with vertical tortuous cracks. Engg. Fract. Mech. 74: 2758-2769

Raghuprasad B K, Bhattacharya G S, Mihashi H 1994 Size effect in Notched concrete plate under plane stress-a lattice model. Int. J. Fract. 67: R3-R8

Ramsamooj D V 1994 Prediction of fatigue life of plain concrete beams from fracture tests. J. Testing and Evaluation 22(3): 183-194

Rashid Y R 1968 Ultimate strength analysis of prestressed concrete pressure vessels. Nuclear Eng. Design 7(4): 334-344

Reinhardt H W 1985 Crack softening zone in plain concrete under static loading. Cement Concrete Research 15: 42-52

Rice J R 1968 Mathematical analysis in the mechanics of fracture. H Liebowitz (ed.), Fracture-An advanced treatise, vol. 2, New York: Academic Press 191-308

Roelfstra P E, Sadouhi H, Wittman F H 1985 Numerical Concrete. Materials and Structures, RILEM 18: 1985 , p. 327

Roelfstra R E, Wittmann F H 1986 A Numerical Method to Link Strain Softening with Fracture in Concrete, Fracture Toughness and Fracture Energy in Concrete, F H Wittmann (ed.), Amsterdam: Elsevier Science 163-175

Schlangen E, Van Mier J G 1991 Experimental and Numerical analysis of Micro Mechanisms of Fracture of Cement based Composites. Report No. 25.5-91-1/VHC

Schlangen E, Van Mier J G M 1992 Simple Lattice Model for Numerical Simulation of Fracture of Concrete Materials. Materials and Structures 25: 534-542

Schlangen E, Van Mier J G M 1992 Experimental and Numerical Analysis of Micromechanism of Fracture of Cement based composites. Cement Concrete Composites 14: 105-118

Shah S P, Swartz S E, Ouyang C 1995 Fracture Mechanics of Concrete: Applications of Fracture Mechanics to Concrete, Rock and other Quasi-brittle Material, New York: John Wiely Sons, Inc

Sitaram P 1993 Ultimate Load Analysis of Reinforced Concrete Folded Plate Structures. Ph.D Dissertation, Kansas State University, Manhattan, KS

Slowik V, Angelo G P, Saouraa V E 1996 Fracture of concrete under variable amplitude fatigue loading. ACI Materials Journal 93(3): 272-283

Smith E 1974 The structure in the vicinity of a crack tip: A general theory based on the cohesive crack model. Eng. Fract. Mech. 6: 213-222

Stuart E S 1982 Crack growth and fracture in plain concrete-Static versus fatigue loading. Fatigue of concrete structures, S P Shah (ed.), SP-75, 3, ACI, Detroit, 47-68

Subramaniam V K, Neil E F, Popovics S J, Shah S P 2000 crack propagation in flexural fatigue of concrete. J. Eng. Mech. ASCE 126(9): 891-898

Sundara Raja Iyengar K T, Raghu Prasad B K, Nagaraj T S, Bharti Patel 1996 Parametric sensitivity of fracture behaviour of concrete. Nuclear Eng. and Design 163: 397-403

Sundara Raja Iyengar K T, Raviraj R S, Jayaram T N 2002 Analysis of crack propagation in strainsoftening beams. Engg. Fract. Mech. 69

Swenson D V 1986 Modeling Mixed-Mode Dynamic Crack Propagation Using Finite Elements: Theory and Applications. Ph.D Dissertation, Cornell University, Ithaca, NY

Tada H, Paris P C, Irwin G R 1985 The Stress Analysis of Cracks Handbook, 2nd ed., Paris Productions, St. Louis, MO

Takashi, Matsumoto, Victor C Li 1999 Fatigue life analysis of fiber reinforced concrete with a fracture mechanics based model. Cement concrete composites 21: 249-261

Toumi Bascos A, Turatsinze A 1998 Crack propagation in concrete subjected to flexural cyclic loading. Materials and Structures 31: 451-458 
Van Mier Jan G M 1997 Fracture Process of Concrete, Assessment of Material Parameters for Fracture Model, CRC Press

Walsh P F 1972 Fracture of plain concrete. Indian Concrete Journal 46: 11

Walsh P F 1976 Crack initiation in plain concrete. Mag. Concrete Res. 28: 37-41

Wawrzynek P A, Ingraffea A R 1987 Fracture Analysis Code (FRANC). Cornell University, Ithaca, NY

Wnuk M P 1974 Quasi-static extension of a tensile crack contained in viscoelastic plastic solid. J. Appl. Mech. Trans. ASME 41(1): 234-242

Yon J H, Hawkings M N, Kobayashi S A 1997 Comparisons of concrete fracture models. J. Eng. Mech. ASCE 123(3): 196-203 